\title{
Interplay between spontaneous and sensory activities in barrel cortex: a computational study Elena Phoka*1, Mark Wildie ${ }^{1}$, Rasmus S Petersen ${ }^{2}$, Mauricio Barahona ${ }^{1}$ and Simon R Schultz ${ }^{1}$
}

\author{
Address: ${ }^{1}$ Department of Bioengineering, Imperial College London, London, SW7 2AZ, UK and ${ }^{2}$ Faculty of Life Sciences, University of Manchester, \\ Manchester, M60 1QD, UK \\ Email: Elena Phoka* - e.phoka07@imperial.ac.uk \\ * Corresponding author
}

from Eighteenth Annual Computational Neuroscience Meeting: CNS*2009

Berlin, Germany. 18-23 July 2009

Published: 13 July 2009

BMC Neuroscience 2009, I0(SuppI I):P35 I doi:I0.II86/I47|-2202-I0-SI-P35 I

This abstract is available from: http://www.biomedcentral.com/I47I-2202/I0/SI/P35 I

(C) 2009 Phoka et al; licensee BioMed Central Ltd.

\section{Introduction}

The observation that cortical neuronal responses to repeated application of the same stimulus have a high degree of "trial to trial" variability has led to the notion that neuronal responses are affected by the intrinsic spontaneous state of the system and are not solely a direct reflection of the sensory input. Complementing this, a number of sources of recent evidence have suggested that ongoing ("spontaneous") spatiotemporal patterns of activity do not merely reflect stochastic network fluctuations and internal noise sources, but can be affected by the recent history of sensory experience. This evidence includes multi-electrode array recordings, voltage sensitive dye imaging $[1,2]$, as well as electron-microscopic evidence of a change in inhibitory synapse density and concomitant physiological changes after a substantial period of whisker stimulation [3]. These observations lead to some interesting questions. Is the spontaneous functional connectivity network itself modified by sensoryevoked activity? And if so, what mechanisms could account for it, and what information processing tasks might such a phenomenon help to perform? We are specifically testing a hypothesis that varieties of spike timing dependent plasticity (STDP) that have been previously documented can account for this effect.

To address these questions, we have developed a biologically inspired model of (initially) a single barrel, consist- ing of approximately 2000 neurons (Izhikevich point neuron model, [4]). We model layers $2 / 3$ and 4 each representing a $200 \mu \mathrm{m} \times 200 \mu \mathrm{m} \times 200 \mu \mathrm{m}$ cube of tissue. The connectivity is random with connection probabilities for each neuron class (layer 2/3: excitatory pyramidal, and inhibitory basket and non-basket; layer 4: excitatory spiny stellate) constrained by data from the physiological literature. STDP occurs at the excitatory synapses. Sensory evoked activity is generated by direct input to layer 4 neurons from a Linear-Nonlinear-Poisson (LNP) model of thalamic nucleus VPm with experimentally recorded thalamic transfer functions [5]. Our model accounts for spontaneous activity in the barrel cortex and allows us to generate specific testable predictions concerning the effect of temporally patterned whisker stimulation on spontaneous spatiotemporal dynamics in barrel cortex. This model may help us to generate and refine hypotheses concerning the role of ongoing network activity in memory consolidation and perceptual learning.

\section{Acknowledgements}

This work was supported by BBSRC.

\section{References}

I. Kenet T, Bibitchkov D, Tsodyks M, Grinvald A, Arieli A: Spontaneously emerging cortical representations of visual attributes. Nature 2004, 425:954-956.

2. Han F, Caporale N, Dan Y: Reverbation of recent visual experience in spontaneous cortical waves. Neuron 2008, 60:321-327. 
3. Knott GW, Quairiaux C, Genoud C, Welker E: Formation of dendritic spines with GABAergic synapses induced by whisker stimulation in adult mice. Neuron 2002, 34:265-273.

4. Izhikevich EM, Edelman GM: A large-scale model of mammalian thalamocortical systems. PNAS 2008, 105:3593-3598.

5. Petersen RS, Brambilla M, Alenda A, Bale MR, Montemurro MA, Panzeri S, Maravall M: Diverse and temporally precise kinetic feature selectivity in the VPm thalamic nucleus. Neuron in press.

6. Petersson KM, et al.: Artificial grammar learning and neural networks. Proc Cogn Sci Soc 2005: 1726-1731.

7. Reber AS: Implicit learning of artificial grammar. J Verb Learn \& Verb Behav 1967, 6:855-863.

8. Çürüklü B: A Canonical Model of the Primary Visual Cortex Mälardalen University Press; 2005.

9. Mountcastle VB: The columnar organization of the neocortex. Brain 1997:70I-722.

10. Gewaltig MO, Diesmann M: NEST. Scholarpedia 2007, 2: 1430.

Publish with Bio Med Central and every scientist can read your work free of charge

"BioMed Central will be the most significant development for disseminating the results of biomedical research in our lifetime. "

Sir Paul Nurse, Cancer Research UK

Your research papers will be:

- available free of charge to the entire biomedical community

- peer reviewed and published immediately upon acceptance

- cited in PubMed and archived on PubMed Central

- yours - you keep the copyright

Submit your manuscript here:

http://www.biomedcentral.com/info/publishing_adv.asp 